\title{
A 'bootstrap' model of the renal medulla
}

\author{
K. E. BRITTON \\ M.Sc., M.D., M.R.C.P. \\ P. E. CAGE \\ B.Sc. \\ E. R. CARSON \\ M.Sc., C.Eng, Ph.D.

\begin{abstract}
Department of Nuclear Medicine, Middlesex Hospital Medical School and Department of Systems Science, City University, London WIN $7 R L$
\end{abstract}

\begin{abstract}
Summary
The 'bootstrap' model of the handling of salt, water and urea by the renal medulla is based on the concepts and data of Stephenson (1972), and Kokko and Rector (1972), and adds support to them. Revision of the traditional counter current hypothesis is necessary since active transport of salt and urea is absent from the inner medulla. This advanced model is structured appropriately and demonstrates how events in the medulla interact and vary with time as change from a diuretic to an antidiuretic state proceeds.
\end{abstract}

\section{Introduction}

The control of solute and water movement in the renal medulla is complex and its understanding has been aided by using engineering concepts such as the counter current multiplier. In this paper the methods that engineers use to investigate control systems (mathematical modelling and dynamic systems analysis) have been applied to the problem. This approach has led to a model which is structured and behaves as the real kidney.

The conventional hypothesis for water conservation by the renal medulla is by means of a counter current multiplier (Kuhn and Ryffel, 1942; Hargitay and Kuhn, 1951; Ullrich, Kramer and Boylan, 1962). This model is used to explain how, in each loop of Henle of the juxtamedullary nephrons, a 'single effect' may be multiplied sufficiently to cause a concentration gradient between cortex and medullary tip, along the long axis of the medulla. The 'single effect' is the active transport by each cell of an ascending limb of sodium ions, but not water, out of its lumen into adjacent interstitial fluid. The concentration of sodium ions is raised locally. Water is drawn out of a portion of an adjacent waterpermeable descending limb and sodium ions tend to diffuse in. The fluid in the descending limb becomes locally slightly more concentrated and then is moved on down the descending limb by the hydrostatic pressure that caused glomerular filtration. The fluid in the descending limb is exposed to the single effect at each stage of its movement through the outer to the inner medulla and at each stage its concentration is increased by the removal of water by hypertonicity of the adjacent interstitium and by the addition of sodium ions by diffusion. This process is thought to continue to the tip of the medulla. The sodiumrich water-poor fluid then leaves the descending limb, rounds the loop and enters the ascending limb. In the ascending limb, sodium ions, but not water, are transferred out of the lumen by the 'single effect' and so at each stage up the ascending limb the fluid becomes progressively more dilute. At any level in the medulla, the 'single effect' is acting on fluid in an ascending limb to make the adjacent interstitium just a little more hypertonic than the fluid in the adjacent descending limb at the same level. Advantage is taken of the fact that the current of fluid travelling in the opposite direction up the ascending limb contains fluid that, at each stage, is only slightly less concentrated than that in the adjacent descending limb. The small single effect is multiplied so that at each level of the descending limb the fluid in it becomes more concentrated. The osmotic gradient so caused acts on the collecting duct fluid to remove water thereby concentrating the urine. The essential energy source for this hypothesis is active salt transport out of the whole length of both the thick and the thin ascending limb.

The evidence for this hypothesis resides in: the anatomical arrangement in the medulla of the nephrons and vasa recta-the latter acting as a counter current exchanger (Lever and Kriz, 1966); in the osmotic gradient found along the axis of the medulla in snap frozen kidneys (Wirz, Hargitay and Kuhn, 1951) and the appropriateness of this engineering concept. It is an essential prerequisite of the hypothesis that active salt transport be present not only in the thick ascending limb but also in the thin ascending limb in spite of the hypoxic environment of the inner medulla. Imai and Kokko (1974) have shown clearly in the teased nephron preparation from the rabbit that active salt transport is not a property of the cells of the thin ascending limb.

Two other features of the conventional counter 
TABLE 1. Simplified summary of permeability characteristics of different parts of the nephron (rabbit)

\begin{tabular}{|c|c|c|c|}
\hline Part of nephron & Water & Sodium ions & Urea \\
\hline$\overline{\text { Descending }}$ & Very permeable & Impermeable * & Impermeable * \\
\hline Thin ascending & Impermeable & Very permeable & Moderately permeable \\
\hline Thick ascending & Impermeable & $\begin{array}{l}\text { Very permeable active } \\
\mathrm{Cl}^{-} \text {pump }\end{array}$ & Impermeable \\
\hline Distal tubule & Permeable with ADH & Partial $\mathrm{Na} / \mathrm{K}$ exchange & Impermeable \\
\hline Collecting duct & Permeable with ADH & Moderately permeable * & $\begin{array}{l}\text { Impermeable except at collecting } \\
\text { duct junctions in inner medulla }\end{array}$ \\
\hline
\end{tabular}

\section{* Varies with different species. \\ ADH, antidiuretic hormone.}

current hypothesis remained awkward. The pressure required to separate concentrated urine and normal plasma by a perfect osmotic membrane is about $\mathbf{3 7}$ atmospheres! This problem is resolved because the situation is dynamic, not static frozen slices. The calculated pressure differences never develop because the osmotic conditions control flows rather than pressures. A dynamic model appears an appropriate representation of the mechanism of water conservation. Secondly, Ullrich and Jarausch (1956) showed that the sodium concentration gradient rose steeply along the axis of the outer medulla but only slightly along the axis of the inner medulla, whereas the urea gradient rose much more steeply along the axis of the inner medulla, a finding inconsistent with the hypothesis that active salt transport is the local driving force in the inner medulla, but rather favouring an important role for urea.

The next major advance came with the demonstration by Stephenson $(1972,1973)$ that passive transport of salt from lumen to interstitium of the thin ascending limb in the inner medulla could be brought about if special assumptions were made about specific impermeabilities of nephron segments to salt, water and urea at differing sites. Such specific impermeabilities have been demonstrated (Burg et al., 1966; Grantham and Burg, 1966; Kokko, 1970, 1972, 1974; Kokko and Rector, 1972; Rocha and Kokko, 1973) and are summarized in Table 1.

Models previously had included free permeability to ions through most nephron segments (Marsh, Kelman and Howard, 1967; Marsh and Segel, 1971). Current models making use of these new data, Table 2, suffer: either from still postulating active salt transport in the thin ascending limb; or from postulating active urea or salt transport in the collecting ducts; or from being a static instead of a dynamic representation of the mechanism of water conservation; or from being insufficiently related to the real structure of the medulla.

\section{The bootstrap mechanism}

The bootstrap system proposed here is a dynamic model which requires neither active salt nor urea $\overrightarrow{\vec{\omega}}$ transport to be present in the inner medulla. The $\frac{\rho}{\circ}$ bootstrap concept has no precise definition but $\frac{0}{3}$ indicates an attempt, in popular and engineering $\frac{3}{\mathrm{o}}$. parlance, to haul oneself up by one's own bootstraps 워 without actually contravening the second law of 8 thermodynamics, because just sufficient energy is iv injected into the system. In the medulla the chloride $N$ pump (Burg, 1972) in the thick ascending limb of the loop of Henle in the outer medulla is the source of energy for the whole medulla as indicated by $\vec{z}$ Stephenson $(1972,1973)$. Considering the physiology of only the main components, salt, water and urea, the bootstrap effect works in the following way. Removal of salt from the lumen of the thick ascending limbs leaves behind water and urea. Th hypotonic solution that is created moves to the dista tubules which are urea-impermeable but waterpermeable under anti-diuretic conditions. Salt is also actively removed (Wright, 1971). In this way a $\stackrel{\square}{\stackrel{2}{2}}$ highly concentrated solution of urea enters the $\overrightarrow{\vec{F}}$ collecting ducts which are also urea-impermeable in $\frac{\circ}{3}$ the outer medulla. Urea moves down collecting ducts to the inner medulla. As collecting ducts join they become apparently increasingly permeable to urea (Kokko, 1974). There, urea is of higher con- 3 . centration than in the adjacent interstitium and thus tends to move down its concentration gradient, increasing the osmolality in the interstitium. This $\hat{O}$ increase in osmolality tends to draw water out of adjacent tubules, the collecting ducts and in particu- 은 lar the descending limbs in the inner medulla. This tends to increase the salt concentration in these saltimpermeable descending limbs and at the same time the salt concentration in the adjacent interstitium is $\%$ reduced by dilution. The fluid in the descending limb $N$ with a relatively high salt concentration rounds the $\underset{\mathrm{C}}{ }$ tips of the loops and enters the water-impermeable, $\sigma^{\circ}$ salt-permeable thin ascending limbs. Salt therefore 0 tends to diffuse down its concentration gradient $\stackrel{\odot}{\overparen{D}}$ from the lumen of the thin ascending limbs to the $\stackrel{\infty}{\rightarrow}$ interstitium. Thus, the osmolality of the inter- $\square$ stitium is increased. This effect tends to draw more water into the interstitium from the collecting ducts 
TABLE 2. Comparison of models of the medulla in the literature

\begin{tabular}{|c|c|c|c|c|c|c|c|c|c|c|}
\hline Properties of model & $\begin{array}{c}\text { Stewart, } \\
\text { and } \\
\text { Valtin, } \\
1972\end{array}$ & $\begin{array}{l}\text { Kokko } \\
\text { and } \\
\text { Rector, } \\
1972\end{array}$ & $\begin{array}{c}\text { Marumo, } \\
\text { Yoshikawa } \\
\text { and } \\
\text { Koshikawa, } \\
1967\end{array}$ & $\begin{array}{l}\text { Badke, } \\
1973\end{array}$ & $\begin{array}{c}\text { Furukawa } \\
\text { et al., } \\
1974\end{array}$ & $\begin{array}{l}\text { Merletti, } \\
\text { Weed } \\
\text { and } \\
\text { Corson, } \\
1973\end{array}$ & $\begin{array}{l}\text { Gianunzio, } \\
1973\end{array}$ & $\begin{array}{l}\text { Packer } \\
\text { and } \\
\text { Packer, } \\
1974\end{array}$ & $\begin{array}{l}\text { Stephenson, } \\
\text { 1972, 1973, } \\
\text { et al., } 1974\end{array}$ & $\begin{array}{l}\text { Cage, } \\
\text { Carson } \\
\text { and } \\
\text { Britton, } \\
1976\end{array}$ \\
\hline Full mass balance & + & - & - & + & + & + & + & + & + & + \\
\hline Isomorphic model & + & + & + & - & + & + & - & - & - & + \\
\hline Interactive system & + & - & + & + & + & + & + & + & + & + \\
\hline $\begin{array}{l}\text { No active thin } \\
\text { ascending limb }\end{array}$ & -+ & + & + & - & -+ & - & & & + & + \\
\hline $\begin{array}{l}\text { No active } \\
\text { collecting duct }\end{array}$ & $+\quad-$ & + & + & + & $+\quad-$ & - & & & + & + \\
\hline Dynamic response & - & - & - & + & + & + & + & + & - & + \\
\hline Comments & & $\begin{array}{l}\text { Fixed } \\
\text { interstitial } \\
\text { conditions }\end{array}$ & $\begin{array}{l}\text { Boundary } \\
\text { conditions } \\
\text { incorrect. } \\
\text { Analogue } \\
\text { model }\end{array}$ & & $\begin{array}{l}\text { Only one } \\
\text { class of } \\
\text { nephrons }\end{array}$ & & $\begin{array}{l}\text { Hydro- } \\
\text { dynamic } \\
\text { model }\end{array}$ & $\begin{array}{l}\text { Hydro- } \\
\text { dynamic } \\
\text { analogue } \\
\text { model }\end{array}$ & & $\begin{array}{l}\text { Proposed } \\
\text { model }\end{array}$ \\
\hline
\end{tabular}

+ , Present in model; -, not present.

and at the same time tends to dilute the interstitial urea. This process re-establishes the urea gradient from collecting ducts to interstitium. Urea diffuses from collecting ducts to interstitium thus increasing the osmolality of the interstitium; more water moves in from the descending limbs and, in so doing, reestablishes the salt gradient and so on. The osmolality of the interstitium continues to rise and water resorption from the collecting duct is thus enhanced. Resorbed water is carried away by ascending vasa recta.

The crux of the matter is that the osmolality in the interstitium depends on the sum of the salt and urea contributions whereas the diffusion of urea depends only upon the passive gradient of urea from collecting duct to interstitium; and the diffusion of salt depends only upon the passive gradient of the ions from thin ascending limbs to interstitium. The model demonstrates how these two gradients are continuously but alternately re-formed in an escalating manner as the diffusion of specific solute and water due to one gradient recreates the other. This is an example of the bootstrap concept because the energy of the chloride pump in the cortex and outer medulla is transduced to the high urea concentration in the collecting ducts which primes the solute gradient interaction to increase the osmolality in the interstitium. The situation may be visualized as salt raising its own concentration by hauling on urea's bootstraps and vice versa.

\section{The bootstrap model}

This dynamic model of the renal medulla is explicitly based on the physiology reviewed above and deals with the osmotic conditions produced within the medulla by changes in the flows of water, salt and urea through the various tubes within it. The structure of the model is directly related to that of the medulla (isomorphic). It includes all its functionally significant components; the contributions of cortical and juxtamedullary nephrons, the latter having reducing numbers towards the papilla; the collecting ducts, vasa recta and interstitium. The known dimensions of nephrons and their permeabilities are taken from the literature (Kokko, 1974; Cage, Carson and Britton, 1976). Active salt transport driven by the chloride pump is assumed only for the thick ascending limb. The model does not require active transport of any solute or water in any tube in the inner medulla. Urea permeability of a collecting duct only increases where collecting ducts join each other in the inner medulla. Mass balance equations are obtained for the entire medulla using typical input conditions from the cortex and, unlike previous models (Table 2), both dynamic responses and steady state profiles are produced in a physiologically feasible manner, for example, to demonstrate the effect of antidiuretic hormone on the system.

The structure of the model (Fig. 1) is made up by dividing the nephrons, vasa recta, collecting ducts and interstitium into terraces, typically twenty from outer medulla to papillary tip. Each terrace therefore contains a segment of the classes of tubes appropriate to that terrace, thus loops of Henle of cortical nephrons are included in the outer but not the inner terraces of the medulla. The flows in these segments are either ascending or descending. Interactions between all segments in a terrace are governed by the permeabilities and other properties of the tubes and interstitium in that terrace and mass balance equations are obtained for each segment and 
The model

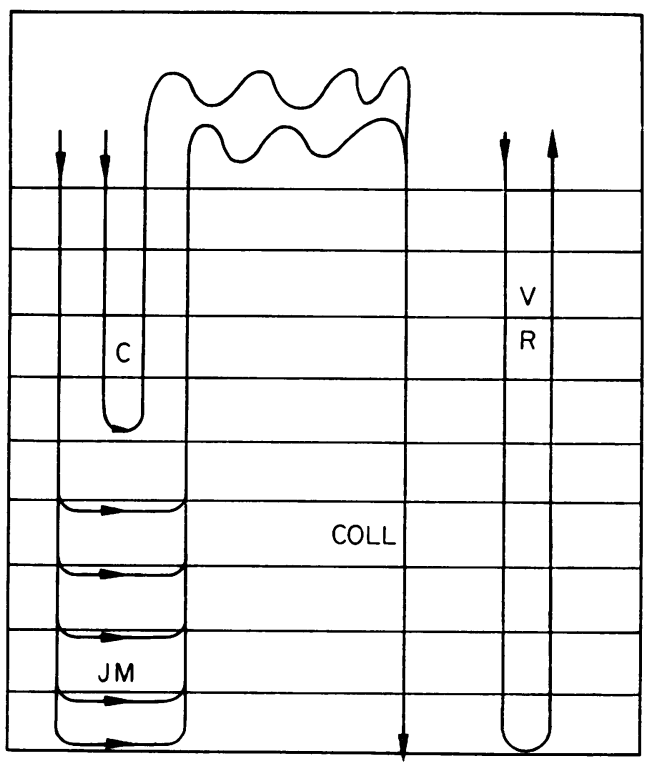

A terrace

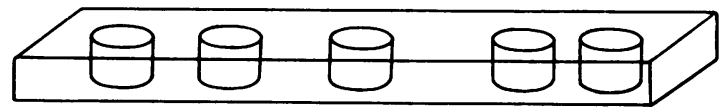

A segment

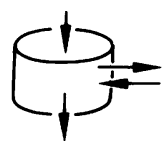

Fig. 1. Diagram of the model structure. C, Class of cortical nephrons; JM, class of juxtamedullary nephrons; COLL, class of collecting ducts; VR, vasa recta.

each terrace. At the same time each class of tubule, nephron, vas rectus and collecting duct is considered individually as the series of segments that make it up so that profiles of the flows and solute concentrations along its length are built up.

For example, a single juxtamedullary nephron is represented by twenty segments of descending limb, eight segments of thin ascending limb, twelve of thick ascending limb, sixteen of distal tubule, and twenty of the common collecting duct. Different loop lengths are accounted for by a different number of segments. The proximal and distal tubules are set in a common terrace representing the whole cortex. The loop of Henle of a single cortical nephron, for example, has twelve segments through the outer medulla. Segments in each terrace then interact with

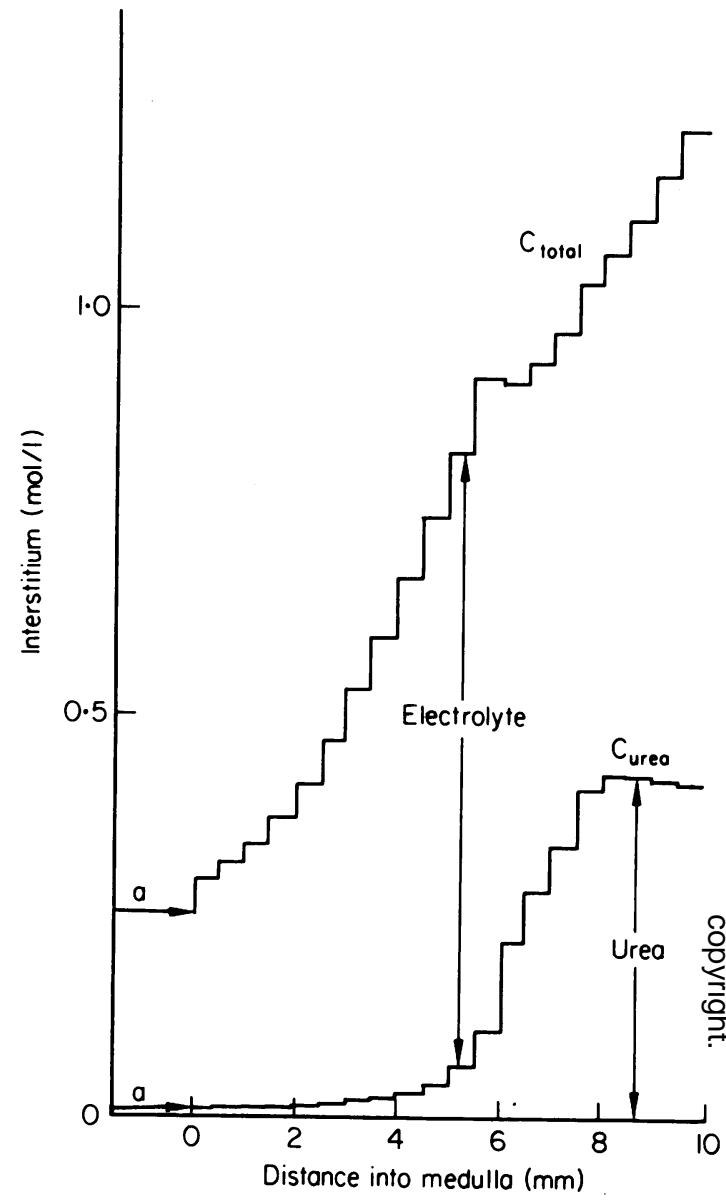

FIG. 2. Spatial variation of conditions within the terraces of the medulla (Fig. 1) in antidiuresis. $C_{\text {total, }}$ total urinary solute concentration in $\mathrm{mol} / \mathrm{l}$; Curea, total urinary urea concentration in $\mathrm{mol} / \mathrm{l}$; ' $a$ ' represents input values.

each other via the interstitium and with adjacent segments in each tube. The system includes one-fifth 8 of juxtamedullary nephrons. The combined effects of all the segments and terraces interacting together are the same as for the whole kidney. The mass balance equations are detailed elsewhere (Cage et al., 1976).

\section{Results and discussion}

The system is set in motion on the computer with typical input conditions, for example isotonicity, and runs in real time until it achieves a steady state. The spatial variation of conditions within the intersti- $\frac{\mathscr{\Phi}}{\mathscr{\Phi}}$ tium in an antidiuretic kidney is given in Fig. 2. It $\stackrel{+}{+}$ may be noted that the total osmolality increases $\square$ progressively from cortex to papillary tip and that, whereas rise in salt concentration contributes most 


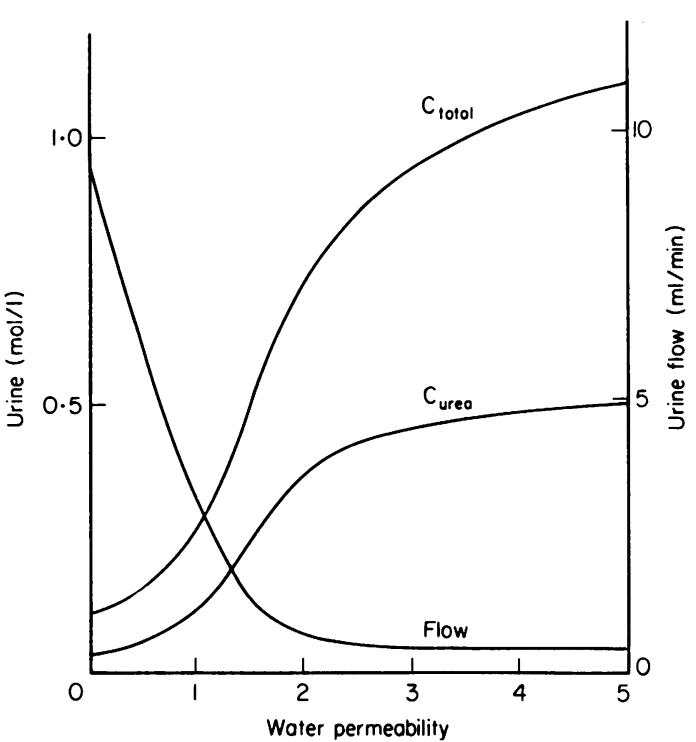

FIG. 3. Effect of variation of water permeability (units $\times$ $10^{-4} \mathrm{~cm}^{4} \mathrm{mmol}^{-1} \mathrm{sec}^{-1}$ ) in the distal tubule and collecting duct. Ctotal, Curea as for Fig. 2.

to the outer medulla, urea plays this role in most of the inner medulla. This fits the original experimental relationship that Ullrich and Jarausch (1956) found for urea and salt profiles along the axis of the medulla. In the bootstrap model, the importance of urea concentration as the energy supply to the inner medulla explains why there is a steeper gradient for urea than salt.

Figure 3 demonstrates the effect of slowly altering the water permeability coefficient of the distal tubules and collecting ducts over the physiological range (from 0.2 to 4 units $\times 10^{-4} \mathrm{~cm}^{4} \mathrm{mmol}^{-1}$ $\left.\mathrm{sec}^{-1}\right)$. This mimics the action of the antidiuretic hormone over its normal physiological range. If water permeability rises above 3 units, a further increase in permeability has relatively little effect on the salt and urea concentration and urine flow since the bootstrap effect is working. When water permeability falls, as in water diuresis, rapid changes in electrolyte and urea concentrations and urine flow are observed. In this situation the bootstrap effect on inner medullary osmolality fails owing to the lack of concentration of urea in the cortex which is necessary to provide energy supply. As an example of its dynamic action, the model takes about 15 min real time to change from a diuretic to antidiuretic state and the conditions in the interstitium and any segment are observable during the transition. In this example, the output of urine falls from 8.7 to $0.45 \mathrm{ml} / \mathrm{min}$; its electrolyte concentration rises from 0.1 to $0.7 \mathrm{mEq} / \mathrm{ml}$ and urea from 0.04 to $0.5 \mathrm{mmol} / \mathrm{ml}$.
Since the model is flexible, the number of segments in each tube and/or the number of terraces can be altered so as to see their effect on the total system (Cage et al., 1976). Alternatively, different input conditions, different permeabilities or different degrees of salt resorption at different sites can be tested. Thus the effects of aldosterone and aldosterone antagonists can be represented and possibly the properties of an ideal diuretic defined.

\section{Conclusion}

The success of the model is judged by its ability to fit existing physiological data without requiring active transport of salt or urea in the inner medulla. This it does while rigidly conforming to the laws of conservation of mass.

The model uses a counter current multiplier only in the outer medulla and a bootstrap effect in the inner medulla. The energy for the bootstrap effect is provided by the energy of the chloride pump in thick ascending limbs and salt transport in distal tubules acting to concentrate urea to prime the urea gradient in the inner medulla. Urea and electrolyte gradients are interacting continually to increase the osmolality in the interstitium in the inner medulla. In antidiuresis, this provides the mechanism and the control of water resorption.

\section{Acknowledgments}

The help of Professor L. Finkelstein and Nicholas J. G. Brown is recognized in this work. Financial support from G. D. Searle Ltd is gratefully acknowledged. Table 1 is adapted from Clinical Physiology, IVth Edition, Campbell, E.J.M., Dickinson, J.R. and Slater, J.D.H., Blackwell, Oxford, 1975.

\section{References}

BADKe, F. (1973) In: Regulation and Control in Physiological Systems (Ed. by A. S. Iberall and A. C. Guyton), p. 436. Instrument Society of America, Rochester.

Burg, M.B. (1972) In: Proceedings 5th International Congress of Nephrology, Mexico, p. 112. S. A. Karger, Basel.

Burg, M.B., Grantham, J., Abramov, M. \& Orloff, J. (1966) Preparations and study of fragments of single rabbit nephrons. American Journal of Physiology, 210, 1293.

Cage, P.E., Carson, E.R. \& Britton, K.E. (1976) (Submitted for publication.)

Furukawa, T., Takasugi, S., Inoue, M., Inada, H., KaJIYA, F. \& ABE, H. (1974) A digital computer model of the renal medullary counter current system. Computers in Biomedical Research, 7, 213.

Gianunzio, J.W. (1973) A multiple model study of flow and transport phenomena in the cardiovascular system. Ph.D. Thesis, University of Wisconsin.

GranthaM, J.J. \& BURG, M.B. (1966) Effect of vasopressin and cyclic AMP on permeability of isolated collecting tubules. American Journal of Physiology, 211, 255.

Hargitay, B. \& KuHn, W. (1951) Das Multiplikationsprinzip als Grundlage der Harnkonzentrierung in der Niere. Zeitschrift für Elektrochemie, 55, 539.

IMAI, M. \& KoKKo, J.P. (1974) Sodium chloride, urea and water transport in the thin ascending limb of Henle. Journal of Clinical Investigation, 53, 393. 
Kokko, J.P. (1970) Sodium chloride and water transport in the descending limb of Henle. Journal of Clinical Investigation, 49, 1838.

Kokko, J.P. (1972) Urea transport in proximal tubule and the descending limb of Henle. Journal of Clinical Investigation, 51, 1999.

KoKKo, J.P. (1974) Membrane characteristics governing salt and water transport in the loop of Henle. Federation Proceedings, 33, 25.

Kokko, J.P. \& ReCToR, T.C. (1972) Counter current multiplication system without active transport in inner medulla. Kidney International, 2, 214.

KUHN, W. \& RYFFEL, K. (1942) Herstellung Konzentrierter Lösungen aus verdunnten blosse Membranwirkung. Ein Modellversuch zur Funktion der Niere. Hoppe-Seylers Zeitschrift für physiologische Chemie, 276, 145.

LEVER, A.F. \& KRIZ, W. (1966) Counter current exchange between the vasa recta and the loop of Henle. Lancet, $i$, 1057.

Marsh, D.J., Kelman, R.B. \& Howard, H.C. (1967) The theory of urine formation in water diuresis with implications for antidiuresis. Bulletin of Mathematical Biophysics, 29, 67.

MARSh, D.J. \& Segel, L.A. (1971) Analysis of countercurrent diffusion exchange in blood vessels of the renal medulla. American Journal of Physiology, 221, 817.

Marumo, F., Yoshikawa, Y. \& Koshikawa, S. (1967) A study on the concentration mechanism of the renal medulla by mathematical model. Japanese Circulation Journal, 31, 1309.

Merletti, R., Weed, H.R. \& CoRson, S.A. (1973) In: Regulation and Control in Physiological Systems (Ed. by A. S. Iberall and A. C. Guyton), p. 442. Instrument Society of America, Rochester.
PACKer, J.S. \& PACKer, J.E. (1974) Recycling of urea in the rat kidney: a dynamic self-regulating analogue computer simulation. Medical and Biological Engineering, 12, 633.

RochA, A.S. \& Kokko, J.P. (1973) Sodium chloride and water transport in the medullary thick ascending limb of $C$ Henle. Journal of Clinical Investigation, 52, 612.

STEPHENSON, J.L. (1972) Concentration of urine in a central $\overrightarrow{\vec{D}}$ core model of the renal counterflow system. Kidneyo International, $2,85$.

STEPHENSON, J.L. (1973) Concentrating engines and the $\frac{\bar{\sigma}}{\bar{\omega}}$ kidney: I and II. Biophysics Journal, 13, 512 and 546.

Stephenson, J.L., Tewarson, R.P. \& Mejia, R. (1974) Quantitative analysis of mass and energy balance in nonideal models of the renal counterflow system. Proceedings ${ }^{\infty}$ of the National Academy of Sciences, 71, 1618.

Stewart, J., Luggen, M.E. \& Valtin, H. (1972) A computer model of the renal countercurrent system. Kidney $\vec{\omega}$ International, 2, 253.

Stewart, J. \& Valtin, H. (1972) Computer simulation of osmotic gradient without active transport in renal inner 3 . medulla. Kidney International, 2, 264.

ULlRICH, K.J. \& JARAUSCH, K.H. (1956) Untersuchungen N zum Problem der Harn Konzentrierung und -verdünnung. $\sigma$ Pflügers Archiv für die gesamte Physiologie, 262, 537.

Ullrich, K.J., KRAMER, K. \& BoYlan, J.W. (1962) In: ĩ Renal Disease (Ed. by D. A. K. Black), p. 49. Blackwell, $v$ Oxford.

Wirz, H., Hargitay, B. \& KuHN, W. (1951) Lokalisation des durch direkte Kryoskopie. Helvetica physiologica et $\vec{Z}$ pharmacologica acta, 9, 196.

WRIGHT, F.S. (1971) Increasing magnitude of electrical potential along the renal distal tubule. American Journal of $\overrightarrow{0}$ Physiology, 220, 624. 